University of Nebraska - Lincoln

DigitalCommons@University of Nebraska - Lincoln

4-15-1999

\title{
Magnetic hardening in $\mathrm{SmCo}_{x}-\mathrm{Co}$ multilayers and nanocomposites
}

\author{
J. Ping Liu \\ University of Nebraska-Lincoln, pliu@uta.edu \\ Yi Liu \\ University of Nebraska-Lincoln, yliu@unl.edu \\ Ralph Skomski \\ University of Nebraska-Lincoln, rskomski2@unl.edu \\ David J. Sellmyer \\ University of Nebraska-Lincoln, dsellmyer@unl.edu
}

Follow this and additional works at: https://digitalcommons.unl.edu/physicssellmyer

Part of the Physics Commons

Liu, J. Ping; Liu, Yi; Skomski, Ralph; and Sellmyer, David J., "Magnetic hardening in SmCox-Co multilayers and nanocomposites" (1999). David Sellmyer Publications. 79.

https://digitalcommons.unl.edu/physicssellmyer/79

This Article is brought to you for free and open access by the Research Papers in Physics and Astronomy at DigitalCommons@University of Nebraska - Lincoln. It has been accepted for inclusion in David Sellmyer Publications by an authorized administrator of DigitalCommons@University of Nebraska - Lincoln. 


\title{
Magnetic hardening in $\mathrm{SmCo}_{x}-\mathrm{Co}$ multilayers and nanocomposites
}

\author{
J. P. Liu \\ Behlen Laboratory of Physics and Center for Materials Research and Analysis, University of Nebraska, \\ Lincoln, Nebraska 68588-0111 \\ Y. Liu \\ Department of Mechanical Engineering and Center for Materials Research and Analysis, \\ University of Nebraska, Lincoln, Nebraska 68588-0111 \\ R. Skomski and D. J. Sellmyer \\ Behlen Laboratory of Physics and Center for Materials Research and Analysis, University of Nebraska, \\ Lincoln, Nebraska 68588-0111
}

\begin{abstract}
$\mathrm{SmCo}_{x}-\mathrm{Co}(x=3.5,4$, and 5) nanostructured multilayers have been prepared by $\mathrm{dc}$ and $\mathrm{rf}$ sputtering. Magnetic hardening has been found in the as-deposited thin films. The effects of the Co and hard-phase layer thicknesses and the effect of the $\mathrm{Cr}$ underlayer have been studied. Further magnetic hardening has been achieved by heat treating the samples. A remarkable increase of the coercivity has been obtained in the nanocomposite films, with coercive force up to $40 \mathrm{kOe}$. Transmission electron microscopy, atomic force microscopy, and magnetic force microscopy observations have been performed to understand the nanostructure and the domain structure. (C) 1999 American Institute of Physics. [S0021-8979(99)61208-7]
\end{abstract}

\section{INTRODUCTION}

Sparked by the discovery of the intergrain exchangecoupling phenomena in the $\mathrm{Nd}_{2} \mathrm{Fe}_{14} \mathrm{~B}-\mathrm{Fe}_{3} \mathrm{~B}$ composite, ${ }^{1}$ much research has been done on exchange-coupled nanocomposite magnets. $^{2-4}$ The purpose of this research is to combine advantages of the hard phase and the soft phase and therefore reach higher energy products. Theoretical calculations have predicted giant energy products for ideal nanocomposite permanent magnets. ${ }^{5,6}$ However, the ideal nanostructured composites are very difficult to prepare experimentally. Recently, we have reported our results on very high energy products (above 50 MGOe) achieved in rapidly thermally processed composite thin films. ${ }^{7}$ In these films, a nearly ideal nanostructure of the homogeneously distributed hard and soft phases has been obtained. More exploratory work on the exchange-coupled nanocomposite films has been underway since then. In this article, we present our investigation of magnetic hardening in $\mathrm{SmCo}_{x}-\mathrm{Co}$ multilayers and heat treated nanocomposite films.

\section{EXPERIMENT}

$\mathrm{SmCo}_{x} / \mathrm{Co}$ multilayer thin films with $\mathrm{Cr}$ underlayer and cover layer were prepared with a multiple-gun dc and rf sputtering system. The $\mathrm{SmCo}_{x}$ and Co layers were deposited onto glass or silicon substrates alternatively. The $\mathrm{SmCo}_{x}$ targets $(x=3.5,4,4.5$, and 5) were either commercial products or homemade by a sintering mixture of $\mathrm{Co}$ and $\mathrm{Sm}$ powders. The fraction of the soft phase Co in the films was estimated from the thickness of the Co layers in the multilayers. Flowing high-purity argon gas was used for sputtering. The pressures were varied from 5 to 30 mTorr. The sputtering parameters in this investigation (including the argon pressure, the power rates of sputtering guns, and the targets-to-substrate distance) were chosen to produce films with maximum coercivity. The thickness of each film was calculated by measuring the mass gain upon deposition.

The nanocomposite films with random nanostructure were prepared by heat treating the as-deposited films in a furnace with vacuum $5 \times 10^{-7}$ Torr or in a rapid thermal annealing device. Generally high coercivity has been obtained only after the heat treatment.

Magnetization loops were measured by an alternating gradient force magnetometer (AGFM) and a superconducting quantum interference device (SQUID) magnetometer. Nanostructure of the films was observed by a transmission electron microscope (TEM). X-ray diffraction and electron diffraction X-ray (EDX) spectroscopy have been used to identify the phase structures of the samples. Magnetic force microscopy (MFM) and atomic force microscopy (AFM) were used to observe the domain structures and the surface morphology.

\section{RESULTS AND DISCUSSIONS}

Bulky Sm-Co materials have been studied extensively in the past decades for their application as permanent magnetic materials. $\mathrm{SmCo}_{5}$ compound has a very high anisotropy field and, hence, can be used to produce magnets with very high coercivity. We chose the compositions $\mathrm{SmCo}_{x}$ of the hard-phase targets with $x$ close to 5 and found that the coercivity of the films was maximized with $x$ close to 3.5 .

As found in earlier studies, in the hard-soft phase composite there is a tradeoff between the remanent magnetization and the coercivity. Coercive force always decreases with an increasing amount of the soft phase. To obtain the highest coercivity in the presence of the soft phase, the morphology of the composite films needs to be controlled carefully.

We reported previously in $\mathrm{PrCo}-\mathrm{Co}$ nanocomposite films that the as-deposited films are amorphous and magneti- 


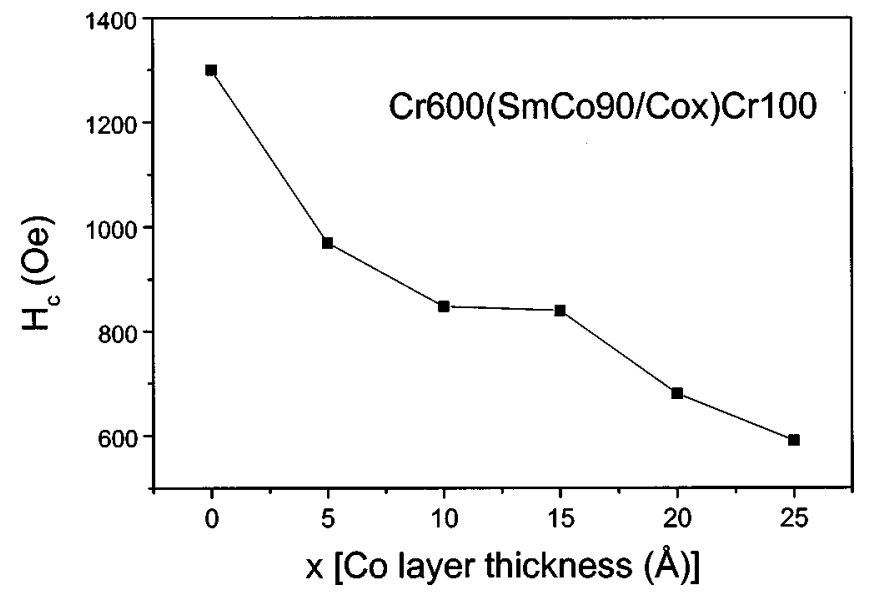

FIG. 1. Dependence of coercivity of the $\operatorname{Cr}(600 \AA) /$ $\mathrm{SmCo}_{4}(90 \AA) / \operatorname{Co}(x \AA) / \operatorname{Cr}(100 \AA)$ film on Co layer thickness.

cally soft. ${ }^{8}$ In the present study the as-deposited $\mathrm{SmCo}_{x} / \mathrm{Co}$ multilayers exhibit considerable coercivity with in-plane anisotropy, which indicates that the magnetically hard phase has been formed upon sputtering under the preparation condition adopted in this experiment. The crystalline structure of the hard phase is still under investigation. The in-plane anisotropy may be related to the grain orientation in the films which is determined by the growth preference of the atomic planes. As we will see later, the in-plane anisotropy remains after annealing.

Figure 1 shows the dependence of coercivity on the Co layer thickness of an as-deposited film. As expected, the coercivity decreases monotonically with increasing Co layer thickness, which indicates that it is important to control the soft layer dimension in order to have high coercivity.

Figure 2 shows the dependence of coercivity of two groups of the bilayer samples, one with the $\mathrm{Cr}$ underlayer and cover layer and another without the Cr layers, with respect to the thickness of the hard-phase layers. It is surprising that for hard-phase layer thicknesses greater than $20 \mathrm{~nm}$, the coercivity decreases slowly with increasing hard-phase thickness. This phenomenon was observed in all the multilayer samples in this investigation. It may be related to

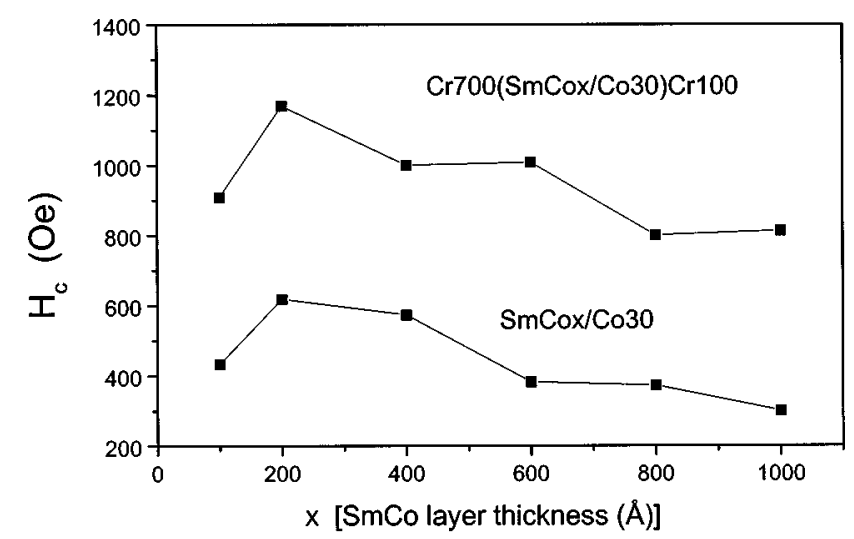

FIG. 2. Dependence of coercivity of the $\mathrm{Cr}(700 \AA) / \mathrm{SmCo}_{3.5}(x \AA) /$ $\mathrm{Co}(30 \AA) / \mathrm{Cr}(100 \AA)$ film and the $\operatorname{SmCo}_{3.5}(x \AA) / \mathrm{Co}(30 \AA)$ on hard-phase layer thickness.

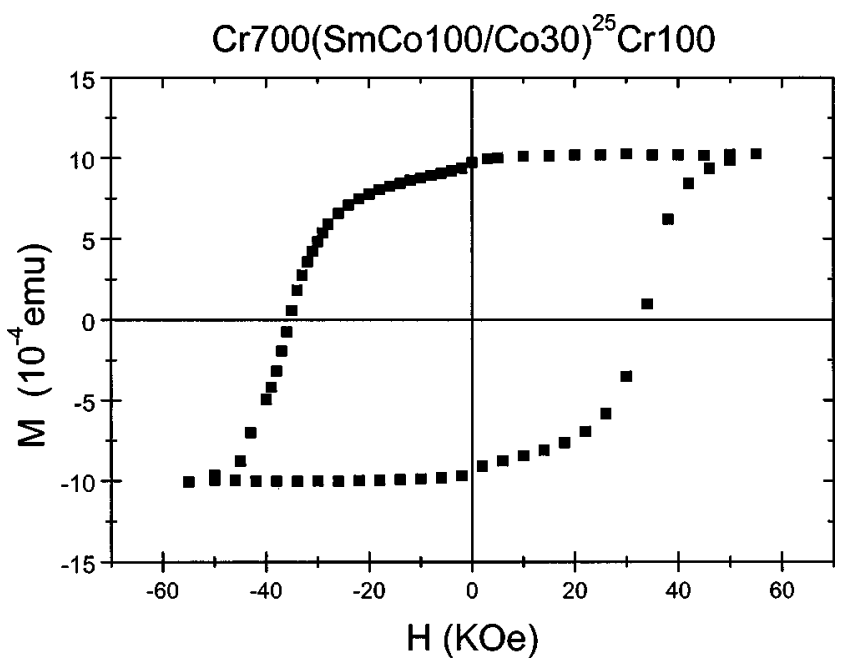

FIG. 3. Hysteresis loop of the $\mathrm{Cr}(700 \AA) /\left[\mathrm{SmCo}_{3.5}(100 \AA) /\right.$ $\mathrm{Co}(30 \AA)]^{25} / \mathrm{Cr}(100 \AA)$ annealed at $500{ }^{\circ} \mathrm{C}$ for $20 \mathrm{~min}$.

the increase of total thickness. It has been reported previously that the coercivity of thin films generally decreases with increasing total film thickness. ${ }^{7,9}$ This has not yet been fully understood, but a likely explanation is that the number of nucleation centers harmful to coercivity increases with the film thickness.

The interesting point of Fig. 2 is that it suggests the importance of a proper morphology to magnetic hardening in the films. An optimal configuration of the films is necessary in order to achieve maximum coercivity. In view of achieving highest energy products in the exchange-coupled nanocomposite magnets, it is also necessary to keep the dimension of the hard phase small so that more soft phase can be distributed homogeneously in the magnets, leading to higher magnetization.

Figure 2 also shows that the $\mathrm{Cr}$ underlayer is useful for developing high coercivity. It has been found that the thickness of the $\mathrm{Cr}$ underlayers needs to be large enough to obtain high coercivity, as has been discussed in the earlier work from this laboratory. ${ }^{10}$ The reason may be that if the $\mathrm{Cr}$ underlayer is thick enough, the enhanced roughness of the underlayer surface will lead to the small grain size of the above magnetic layers. In this experiment, the highest coercivity achieved required the thickness of the $\mathrm{Cr}$ underlayer to be greater than $60 \mathrm{~nm}$.

Further magnetic hardening is realized by heat treating the films. Figure 3 shows the hysteresis loop measured in a direction parallel to the film plane after being annealed at $500{ }^{\circ} \mathrm{C}$ in vacuum for $20 \mathrm{~min}$. The annealed samples also show in-plane anisotropy which means that the annealing does not alter the grain orientation of the film. The coercivity was dramatically increased with heat treatment. Nearly 40 kOe coercive force has been obtained even though this is only a minor loop. This coercivity value is comparable to the highest coercivity value reported thus far for single-phase Sm-Co systems.

Similar enhancement of coercivity can be also obtained by treating the samples in rapid thermal processing (RTP) equipment. This equipment can attain a temperature up to 


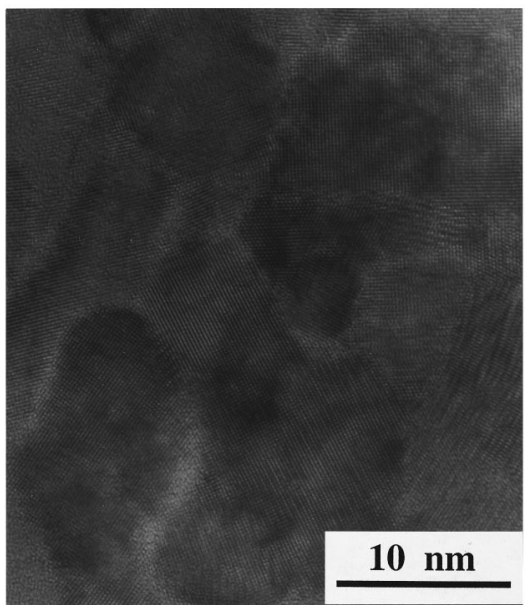

FIG. 4. High-resolution TEM image of $\mathrm{Cr}(700 \AA) /\left[\mathrm{SmCo}_{3.5}(500 \AA) /\right.$ $\mathrm{Co}(25 \AA)]^{2} / \mathrm{Cr}(100 \AA)$ bilayer film annealed at $500{ }^{\circ} \mathrm{C}$ for $30 \mathrm{~s}$

$800^{\circ} \mathrm{C}$ and heating rate up to $200^{\circ} \mathrm{C} / \mathrm{s}$ with total treatment time as short as a few seconds.

To understand the remarkable increase in magnetic hardening, TEM examination has been performed on the annealed samples. Figure 4 shows the high-resolution image of the annealed sample. One can see from the picture that the average grain size is less than $10 \mathrm{~nm}$. The diffraction pattern in a selected area can be matched to hexagonal Co and the $\mathrm{SmCo}_{3}$ phase with $\mathrm{DO}_{19}$ structure. This suggests that the soft phase is $\mathrm{Co}$ and the hard phase is $\mathrm{SmCo}_{3}$. We noticed that this composition is slightly different from the target composition. The reason needs to be explored further. As found in the as-deposited samples, magnetic hardening is degraded by increasing the soft-phase fraction.

AFM and MFM studies also have been performed as shown in Fig. 5. From Fig. 5 one can clearly see that the domain size is more than ten times larger than the grain size. In this case, interaction domain should be taken into account. ${ }^{11}$ Further investigation of the coercivity mechanism is needed.

\section{SUMMARY}

Magnetic hardening has been realized in $\mathrm{SmCo}_{x}-\mathrm{Co}$ $(x=3.5$ and 4) as-deposited multilayers and the annealed nanocomposite films. High coercivity up to $40 \mathrm{kOe}$ has been achieved in the heat treated samples. It has been found that a sufficiently thick $\mathrm{Cr}$ underlayer is necessary for the magnetic hardening. Increase of the soft phase in the composites de-

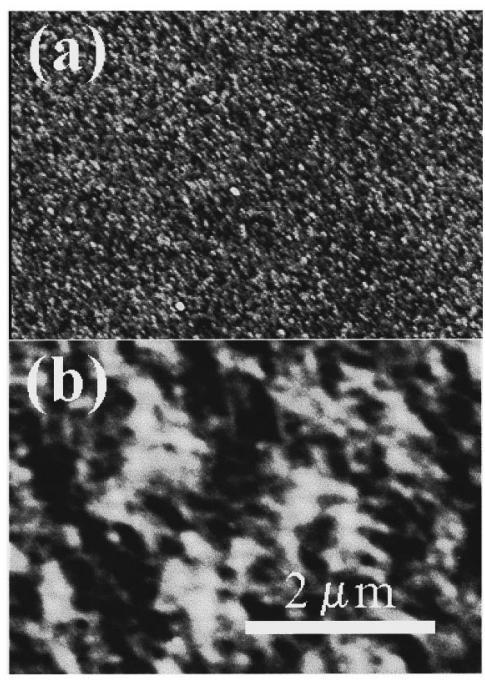

FIG. 5. AFM (a) and MFM (b) images of the $\mathrm{Cr}(700 \AA) /\left[\mathrm{SmCo}_{3.5}(500 \AA) /\right.$ $\mathrm{Co}(25 \AA)]^{2} / \mathrm{Cr}(100 \AA)$ bilayer film.

grades the magnetic hardening. Optimal dimensions for the hard and soft phases are required to reach maximum magnetic hardening. Further study of the magnetic hardening mechanism, the magnetic anisotropy, and the difference of the hardening mechanisms in the as-deposited and the annealed samples, and an effort to achieve a high energy product of the exchange-coupled magnets are still underway.

\section{ACKNOWLEDGMENTS}

The authors are grateful for Professor S. H. Liou for his help in AFM and MFM observations. This research was supported by AFOSR, US DOE, NSF and CMRA.

${ }^{1}$ R. Coehoorn, D. B. de Mooij, and C. de Waard, J. Magn. Magn. Mater. 80, 101 (1989).

${ }^{2}$ P. G. McCormick, W. F. Miao, P. A. I. Smith, J. Ding, and R. Street, J. Appl. Phys. 83, 6256 (1998).

${ }^{3}$ T. Schrefl, J. Fidler, and H. Kronmüller, Phys. Rev. B 49, 6100 (1994).

${ }^{4}$ E. E. Fullerton, J. S. Jiang, C. H. Sowers, J. E. Pearson, and S. D. Bader, Appl. Phys. Lett. 72, 380 (1998).

${ }^{5}$ R. Skomski and J. M. D. Coey, Phys. Rev. B 48, 15812 (1993).

${ }^{6}$ R. F. Sabiryanov and S. S. Jaswal, J. Magn. Magn. Mater. 177-181, 989 (1998).

${ }^{7}$ J. P. Liu, C. P. Luo, Y. Liu, and D. J. Sellmyer, Appl. Phys. Lett. 72, 483 (1998).

${ }^{8}$ J. P. Liu, Y. Liu, Z. S. Shan, and D. J. Sellmyer, IEEE Trans. Magn. 33, 3709 (1997).

${ }^{9}$ E. E. Fullerton, J. S. Jiang, C. Rehm, C. H. Sowers, S. D. Bader, J. B. Patel, and X. Z. Wu, Appl. Phys. Lett. 71, 1579 (1997).

${ }^{10}$ D. J. Sellmyer, Z. S. Shan, Y. Liu, S. H. Liou, S. S. Malhotra, and B. W. Robertson, Scr. Metall. Mater. 33, 1545 (1995).

${ }^{11}$ W. Rave, D. Eckert, R. Schäfer, B. Gebel, and K.-H. Müller, IEEE Trans. Magn. 32, 4362 (1996). 